\title{
SCHOPENHAUER EN LA PERSPECTIVA DE ORTEGA
}

\author{
Carlos E. GARCÍA LARA \\ Universidad de Alicante
}

\section{Literatura y pensamiento: el lugar de Ortega en el cambio de siglo}

EL HOMBRE COMO "HEREDERO".- Es conocida la prioridad y la originalidad que Ortega se arroga en el "descubrimiento" del pensamiento alemán para el público hispano. En ocasión de dirigirse a sus lectores alemanes, les recuerda con orgullo la labor realizada en su propio país como embajador de la cultura germánica, llegando a afirmar: "Alemania no sabe que yo, y en lo esencial yo solo, he conquistado para ella, para sus ideas, para sus modos, el entusiasmo de los españoles. Y algo más. De paso, he infeccionado a toda Sudamérica de germanismo"1. Su vocación de pedagogo, que tenía a España por alumna predilecta, encontró en el pensamiento científico y filosófico del mundo germánico ${ }^{2}$ profundidad y actualidad de temática, rigor de pensamiento y disciplina en el trabajo intelectual. Sus iniciativas para volver a entroncar la cultura española en la europea, tomaron a la alemana como mentor privilegiado.

Indudablemente esta pretensión innovadora no podía tener una validez absoluta, y se contradice con la misma doctrina orteguiana de considerar la historia particular de cada ser humano inmersa en un precipitado de todas las fuerzas históricas que han construído y obrado dialécticamente en su circunstancia. Afirmando en cada ocasión la particularidad insustituible de cada cual en el mundo, y en su

1 "Ortega y Gasset, J. Obras Completas.T. 8, p.25. Cito por la edición de Alianza Editorial, Madrid, 1987, (12 tomos).

2 "[...] durante tres años he sido una pura llama celtíbera que ardía, que chisporroteaba de entusiasmo dentro de la universidad alemana[...] Luego, he continuado años y años sumergido en la ciencia alemana hasta casi ahogarme." (T.8, p.20). 
tiempo, Ortega considera que la naturaleza del hombre viene dada por su herencia histórica. Es decir, el hombre es "heredero". Y esto le es así de manera inevitable, pero eludible. Inevitable porque la inscripción humana de cada viviente de nuestra especie comparte con el forzamiento que impone la transmisión genética de sus características, una transmisión de formas y contenidos culturales que le constituyen en lo psíquico y le inscriben en lo social como miembro de la especie. Este forzamiento cultural es previo a cualquier opción individual del sujeto, y toma sus características propias de los diferentes niveles espaciales y temporales que se concretarán en la circunstancia que a cada cual le toca vivir.

Pero si la presencia de la "circunstancia" constituye lo universal de la herencia cultural que recibe el sujeto, en lo particular de su tiempo de existencia su condición de "heredero" le confronta con su reponsabilidad personal. La dimensión ética de su acto queda así abierta, al tiempo que comprometida. Frente a esta herencia inevitablemente recibida, el sujeto se encuentra convocado a asumirla $o$, por el contrario, eludirla. De su elección dependerá el vivir en la "autenticidad" a través de la realización de la "vocación", o en el extravío de la falsificación de la existencia. Quien escoge la gravedad de la responsabilidad de asumir la circunstancia que le ha tocado vivir, podrá aportar su personal, su única "perspectiva" en la tarea colectiva de la construcción de la verdad del hombre y del mundo.

Pero esta tarea, para Ortega, es tanto individual como generacional. La "generación" también se hace sujeto de responsabilidad histórica. Ortega recoge y sistematiza la conciencia generacional que surgió en el romanticismo. La "generación" se individualiza en su pluralidad de sujetos, por su conciencia de representar y aportar una nueva postura y una nueva perspectiva sobre el mundo. Diferenciada así de los hombres y de los hechos de tiempos precedentes, la "generación" se convierte en impulso de la historia, y en su especificidad generacional le cabe la responsabilidad de producir aquella parte de saber, y aportar aquella parte de verdad que le está reservada en el concierto del devenir de las civilizaciones. La "generación" es un espacio y una temporalidad intermedio entre lo individual y la masa social. Su huella baliza y da cuenta de la emergencia de las personalidades excepcionales, así como pauta los tiempos largos de la historia de los pueblos. Cada generación, pues, queda también convocada a realizar su "personal" contribución, la cual, en multitud de ocasiones, suele ir marcada con los signos de la exigencia de innovación, de producir lo "único", exigencia de "originalidad" que va abriendo los distintos campos socioculturales a la realización de todos los ensayos posibles a lo largo de los dos último siglos.

Sin negar, pues, lo excepcional de la figura de Ortega, y siguiendo su propia doctrina, debemos situar su pretensión fundadora de la "germanización" cultural de la España de comienzos del siglo XX en el contexto generacional, intelectual y filosófico, del cambio de siglo. 
La conciencia "pedagógica" de Ortega encuentra su precedente en el siglo XIX. La primera andanada de reformismo cultural que entendió también el carácter motriz que debería tomar la educación en el proyecto de una "pedagogía social" transformadora de hábitos y conductas, de actitudes y de horizontes nacionales ya vino de alemania, y fue realizada por las gentes del krausismo, filosofía que Sanz del Río acomodó a la ideosincrasia española. La Institución Libre de Enseñanza fue su prolongación y su brazo ejecutivo, contituyéndose en la alternativa liberal y secular al tradicionalismo católico, y que formaría a buen número de las minorías progresistas de aquella generación. Tenemos, pues, que el idealismo alemán, a través del krausismo, arraigó en la España de la segunda mitad del siglo diecinueve, siendo el discurso dominante entre la intelectualidad española al comienzo del último cuarto de siglo. Sin entrar a comentar porqué le cupo a la filosofía de Krause este lugar en la historia cultural española, me interesa señalarlo tanto por su valor de índice, como por su contribución al hecho de que la cultura alemana, que vivía un momento de expléndida creatividad, fuera causa de admiración y fuente de inspiración para las mentalidades progresistas españolas en aquella segunda mitad del siglo. Por su parte, el mundo alemán descubre, valora y aprecia entusiastamente durante este siglo diecinueve a la cultura española, su tradición, su historia, su arte $y$, particularmente en el caso de Schopenhauer, su literatura..

Es este "suelo" filosófico español krausista de elevados ideales éticos y religiosos el que viene a ser hoyado por el "pesimismo" de Schopenhauer, cuando el filósofo José Perojo y Figueras ${ }^{3}$ inicia el hostigamiento al idealismo kraussista español en 1875. Y es curioso hacer notar que el mismo espíritu iconoclasta que movió a Schopenhauer en su polémica filosófica con Hegel, y con el idealismo en general, parece haber estado presente en las motivaciones que llevaron a Perojo a promover la lectura de Schopenhauer en nuestro país "en contra" de la versión krausista _la cual parecía haberse enseñoreado como la "única depositaria de la verdad absoluta" _, obra de "destrucción" que parece haber sido conscientemente perpetrada, y dada por exitosa antes de la última década del siglo. Considerando el breve lapso de tiempo de esta empresa, se puede afirmar que su rápido arraigo y difusión entre nosotros hacen del pensamiento del filósofo alemán un referente habitual para nuestros intelectuales, aunque sea para posicionarse críticamente frente a él.

Tal vez sería, entonces, más comedido y más exacto, reservar a Ortega el papel de líder de aquella generación que él mismo denomino "Generación de 1914", el cual, empapado de "castellanía" y de filosofía y ciencia alemanas, trataría de abrir España al encuentro de Europa. La labor seguida desde Sanz de los Ríos por

3 Cf. SANTIAGO, Donald: "La recepción de Schopenhauer en España", en Anthropos, col. Documentos n6, octubre 1993, pp.146-155.

4 Citado en Santiago, Donald, op. cit. p.148. 
"krausistas", "institucionistas", "regeneracionistas", de hombres como Emilio Huelin que, en la segunda mitad del siglo XIX, daba noticia a los españoles interesados sobre las novedades científicas del mundo anglo-alemán, y el bloque poroso de la generación del noventa y ocho, habían abierto la brecha y andado cierto tramo del camino que debería llevar a España hacia una profunda regeneración de sus hábitos de comportamiento y de sus actitudes intelectuales. Si unos pusieron el acento más en la renovación de los individuos y en la vía de la meditación, y otros en la transformación del país a través de la acción política y pedagógica, si unos se decantaron por el "casticismo" - como Unamuno y Maeztu—, mientras que otros lo hacían por el "europeísmo", todos ellos parecieron encontrar en ideas procedentes de Alemania el estímulo y la orientación conveniente que les ayudara a salir de siglos de postración y aislamiento, a partir de la reflexión sobre el tópico de "España como problema".

EL ESTILO Y LA IDEA.- El referente intelectual y estético de Ortega había sido la cultura francesa, lo mismo que para cualquier liberal español desde finales del siglo dieciocho. Sus lecturas infantiles y juveniles estuvieron allí dirigidas, y Ortega pudo localizar en Renan a su alter ego espiritual. Sin embargo, a la hora de transpasar ese referente personal al conjunto de España, Ortega encuentra deficiencias insalvables. No es sólo que el conservadurismo político de una aburguesada y confortable sociedad autosatisfecha, como es la Francia triunfante de la represión de la Comuna de París, no pueda servir como modelo para la regeneración que España necesitaba, sino que cuando la filosofía se hace "reflexión sobre la compleja metodología de las ciencias", entonces la "verdad" se convierte en "un producto germánico ". Así pues, para Ortega Alemania había tomado el relevo de la Francia ilustrada y revolucionaria, enseñoreando la cultura del siglo diecinueve como esta lo había hecho con la del dieciocho.

De todas formas, tal vez la impronta de esta temprana formación en la sensibilidad y en el gusto por el genio y la ficción de la cultura francesa, quedaron en la personalidad de Ortega en la forma de su orientación hacia la "bella forma" en la expresión, y en la amplitud que ocupó el arte y la literatura entre sus múltiples y variados intereses especulativos.

Pero también su circunstancia española puede ser invocada para dar cuenta del peso de la presencia de la literatura en su vocación filosófica. Sin duda, en la España de la generación anterior habían sido mayoritariamente los literatos, aquellos intelectuales que habían tomado a su cargo la tarea de pensar tanto lo universal de la condición humana, como lo específico de "lo español" en el concierto de las culturas. Tal vez Unamuno - pensador, novelista, poeta-, el interlocutor elegido por Ortega para sus debates intelectuales y generacionales, represente bien el modo

Ortega y Gasset, J., Tomo 1, p.207. 
de transición entre una generación de literatos-pensadores, y otra de pensadoresliteratos. Si en la generación del noventa y ocho el pensamiento filosófico - particularmente Schopenhauer y Nietzche-y político aparece infiltrado en las creaciones de ficción, en Ortega, el pensamiento tiende hacia el sistema, mientras que la preocupación política llega a la acción institucional. Pero no por ello la preocupación estética se suprime. Ortega hace del estilo una exigencia, tanto en el verbo como en la escritura, al punto que nadie le negaría hoy la categoría de estilista de la lengua española.

Recordemos el enojo que le provocaba a Ortega lo que él parecía vivir como una intromisión de aquellos en un campo, como el filosófico, del que parecía tener conciéncia de ser el "fundador" en lengua española. Particularmente crítico fue con las prospecciones filosóficas de Azorín y Baroja, precisamente en referencia a los pensadores alemanes antes mencionados. Tal vez con ello Ortega quería marcar una de las diferencias generacionales que les separaban. Aunque Ortega se benefició practicando la metodología de los noventayochistas de utilizar la crítica literaria como vehículo de sus debates sobre los grandes temas del pais, no parecía dispuesto a dar por bueno que los literatos pudieran salirse de su creación poética para plasmar sus reflexiones filosóficas.

Sin embargo, su decisión de adoptar el género periodístico para sus artículos menores, y el género ensayístico para sus escritos filosóficos parecen indicarnos la marca de la apropiación que de la literatura de creación hizo para sí Ortega. Indudablemente que todo ello respondía también a una táctica dentro de la estrategia general de su "pedagogía social". Ortega sabía de la falta de hábito que tenía el público lector español para abordar las obras filosóficas. Severidad y sistema en la exposición del pensamiento eran aspectos que suscitaban la reticencia inmediata de sus paisanos. Por ello, era partidario de la inclusión de la seducción formal junto a la hondura de las reflexiones, de la imaginación cradora junto al rigor lógico en el pensamiento. De cómo Ortega llegó a cumplir este objetivo en sus textos, da cuenta el efecto indeseado que dio ocasión a la polémica ${ }^{6}$ que dividió a sus lectores en partidarios y detractores del filósofo, según considerasen que lo era, y además, con un estilo elegante y atractivo, o aquellos otros que le consideraban como un buen literato que, además, portaba un bajage de profundas ideas sobre su pueblo, el hombre y el mundo.

Tomando a los escritores como interlocutores Ortega parecía reclamar tanto un lugar de proximidad junto a ellos, como reconocerles en tanto tenían una perspectiva personal sobre la vida. Si utilizó El Quijote como pre-texto de la obra inau-

* Ortega muestra así su enojo frente a este efecto de su estilo: "¡Yo he tenido que aguantar en silencio durante treinta años que los tontainas me acusen de no hacer más que literatura, y lo que es peor, que mis discípulos mismos, crean debido plantear la cuestión de que si lo que yo hacía era literatura o filosofía y ridiculeces provincianas de este jaez!" O.C.T.9, p.404 n. 
gural de su pensamiento —idea de "yo—circunstancia"-, también están sus escritos sobre las obras de Baroja, Azorín, y Gabriel Miró, amén de multitud de pequeños otros textos puntuales sobre otros tantos autores y sus obras. La revalorización de la mirada como estrategia, y la posición de el espectador como actitud constituyen un par epistémico en Ortega, impregnado de los valores literarios y estilísticos de un Azorín o un Gabriel Miró, a los que el filósofo añade la profundidad de su reflexión y la vitalidad de su entusiasmo en la tarea de la renovación cultural de su pueblo.

Son Baroja y Azorín los escritores sobre los que Ortega se detiene más tiempo, con más atención, y también - particularmente en el caso de Baroja-con más apasionamiento ${ }^{7}$. Sus estilos y sus temáticas sirven a Ortega para ilustrar modos dialécticos del posicionamiento de "lo español" frente al mundo. En ambos coincide en alabar la calidad literaria de sus obras, y su decisión en la denuncia de algunas de las lacras que tradicionalmente han tarado el alma española. Pero al cometido de nuestro artículo le interesa más resaltar el hecho de que son ambos autores representantes destacados del magisterio espiritual que supuso Schopenhauer para toda su generación.

En Baroja este magisterio encuentra su manifestación más lograda en su novela capital El árbol de la ciencia. Allí, el infortunio de su protagonista acrisola la visión schopenhaueriana del hombre, en franca oposición a la "teoría de la felicidad" que Ortega delinea en su escrito sobre aquél. Frente al negativismo con el que Baroja y toda su generación abordaron el unamuniano "me duele España", Ortega propone y defiende un vigor vital y positivo, una afirmación a priori de la "voluntad de vivir", fundado en la "reabsorción de la circunstancia" como "destino concreto del hombre" . Nada más lejos, pues de una actitud de desesperanzado quietismo frente al mundo que a cada cual le ha tocado vivir. La limitación que impone la circunstancia concreta toma en Ortega, no el rango de determinismo y dolor existencial, sino el valor heurístico de centramiento desde el que alcanzar el cono-

\footnotetext{
7 Puede sorprender que no haga mención de Unamuno en este punto, habida cuenta, por un lado, de su temprana admiración por Schopenhauer y la afinidad temática de sus respectivas obras, y, por otro lado, de la intensa relación de aquél con Ortega. El apasionado y duradero debate que los dos intelectuales españoles sostuvieron durante casi dos décadas excede en mucho el propósito de este artículo. Sin embargo, entiendo que la fuente filosófica que Ortega reconoce en Unamuno es la del pensamiento de Kierkegaard y no la del alemán. Así, por ejemplo, en La idea de principio en Leibniz..., (O.C.T.8) Ortega señala: "[...]desde mis primeros escritos he opuesto a la exclusividad de un "sentido trágico de la vida" que Unamuno retóricamente propalaba, un "sentido deportivo y festival" de la existencia, que mis lectores, claro está, leían como una frase meramente literaria. (p.297)" "Esa idea del sentimiento trágico de la vida es una imaginación romántica y como tal, arbitraria y de un tosco melodramatismo. El romanticismo envenenó el cristianismo de un hombre histrión-de-raíz que había en Copenhague: Kierkegaard, y de él pasó la cantilena a Unamuno primero y luego a Heidegger. (p.299)" Para mayor abundancia en el tema, remito al lector al estudio de Paulino Garagorri Unamuno y Ortega, donde se recoge además una bibliografía orientadora.
}

8 Ortega y Gasset, J., O.C.T.I, p.322. 
cimiento y la sintonía consigo mismo y con su mundo, que será lo que le permitirá orientarse en su existencia: "saber a qué atenerse" como máxima ética.

En el caso de Azorín, la crítica de Ortega no se situa tanto respecto a la presencia de Schopenhauer en novelas como La voluntad, sino más bien sobre el terreno de la plasmación explícita de las ideas. Precísamente como queriéndole proteger en su calidad literaria, Ortega señala en Azorín su desprecio por el "contenido de las cosas", y admite que haya leído al filósofo alemán "solamente" para enriquecer su estilo literario, habida cuenta de la sorprendente ecuación que realiza Ortega, y por la que "gran literato" equivale a "gran sofista", y esto a "mal filósofo", teniendo como último soporte de toda la fórmula el hecho de ser "un mal hombre"9. Destaquemos, por último, que tampoco "el poder de la persistencia y la monotonía" que, según Ortega, representaba para Azorín "la última sustancia del mundo"10 eran aspectos a compartir por el filósofo madrileño. Sin negar lo acertado de detectar su presencia en las peores inercias de la vida nacional, Ortega discrepaba en limitarse a constatar su acción destructiva, entendiendo esto como una forma de suicidio individual y colectivo.

\section{El mundo como "representación", y el mundo como "circunstancia" y "pers- pectiva".}

Sin negarle a Schopenhauer un lugar entre "los grandes pensadores que fulguraron sobre Alemania"" , Ortega no desaprovecha ocasión para hacer la crítica de sus ideas. Nuestro filósofo podía ser rotundo en sus juicios ${ }^{12}$, de tal forma que el

Ortega y Gasset, J., O.C.T.10, pp. 52 y 54.

in Ortega y Gasset, J., O.C.T.2, p.177.

1 Ortega y Gasset, J., O.C.T.6, p.267.

12 *Referencias a Schopenhauer en las Obras Completas de José Ortega y Gasset:

Tomo 1, pp.: 50 ("Poesía vieja, poesía nueva" en Moralejas II [1906]), 79 (Viaje a España en 1718 [1908]), 157 ("La visión de la historia-San Pedro y San Pablo", en Una polémica I [1910]), 198 ("El hombre oriental", en Arte de este mundo y del otro IV [1911] ), 244 (Sobre el concepto de sensación [1913]).

Tomo 2, pp.: 91 (“La "acción" como ideal”, en Ideas sobre Pío Baroja XI [1916]), $18 \mathrm{I}$ ("Poeta de la costumbre", en Azorín: primores de lo vulgar [1917]), 337 (Incitaciones: Apatía artística [1921]), 400 (Estudios filosóficos: Las dos grandes metáforas (en el segundo centenario del nacimiento de Kant [1924] ), 430 ("Ideas de los castillos: la muerte como creación", en Notas de vago estio [1926]), 529 (La interpretación bélica de la historia [1927] ).

Tomo 3, p.: 381 ("Irónico destino", en La deshumanización del arte [1925] ).

Tomo 6, pp.: 25 (Historia como sistema VI [1941]), 267 ("A "Pedagogía general derivada del fin de la educación", de J.F. Herbart I, en Prólogos [1914]), 298 ("Continuidad y discontinuidad", en Prólogos: "A "Historia dela filosofía", de Karl Vörlander" [1921] ), 416 n ("Pensamiento y "progreso hacia sí mismo" en Aristóteles", en Prólogos: "A "Historia de la filosofía", de Emile Bréier" [1942]).

Tomo 7, pp.: 15 ("Sentido de las nuevas humanidades", en Proyecto del Instituto de Humanidades [1948] ), 309 (¿Qué es filosofia? lección III [1930]), 377 (¿Qué es filosofia? lección VIII [1930]), 401 (¿Qué es filosofia? lección IX [1930]). 
razonamiento en el que estos se apoyaban quedaba ensombrecido por la vibración de la valoración subjetiva - sin duda correspondiente al efecto de "las atalayas del deseo" desde las que El Espectador contempla el panorama que de su circunstancia vital le da su perspectiva personal. En el caso de Schopenhauer llega a rayar en el insulto. A veces pareciera como si en un ejercicio de especularización con su interlocutor alemán, Ortega reprodujese la peculiar forma de "argumentación" que toman algunas de las críticas que ambos realizaban a sus respectivos contrincantes ideológicos. Así, si Schopenhauer podía decir a sus colegas Hegel y Schelling, y arrojar a los "burócratas" de la filosofía "cordilleras de insultos" concluir, como he señalado anteriormente, que Schopenhauer era un "mal filósofo" porque era "un mal hombre" 14 . Hemos de tener en cuenta que aunque Schopenhauer no aparece en resalte para Ortega como un "contrincante" con el que debatir su propio pensamiento, sin embargo, los conceptos cruciales del filósofo alemán acerca del carácter de "Representación" y "Voluntad" que tiene el mundo comprometen el pensamiento de Ortega en varios de sus ejes mayores. Veamos.

La idea de "el mundo como representación" es uno de los puntos donde Ortega se posiciona decididamente frente a Schopenhauer. La constestación mayor a este punto central de la filosofía schopenhaueriana la encontramos en sus conferencias acerca del ser de la filosofía, dictadas en Madrid en 1929. En este momento Ortega se encuentra en la madurez de su propio pensamiento. La incorporación de distintas "fuentes"15 de la filosofía, mayoritariamente alemanas, y el empuje producido por su reciente lectura de Heidegger hacen que Ortega reformule las ideas que viene exponiendo desde 1914 en una definición mucho más acabada.

Tomo 8, pp.: 38-39 (Prólogo para alemanes 3 [1934]), 296 ("El lado dramático de la filosofía", en La idea de principio en Leibniz y la evolución de la teoría deductiva, 31 [1947]), 308 n ("El lado jovial de la filosofía", en La idea de principio en Leibniz y la evolución de la teoría deductiva, 32 [1947] ), 340 ("Apéndices I: Del optimismo en Leibniz", en La idea de principio en Leibniz y la evolución de la teoria deductiva, [1947]).

Tomo 9, p.: 281 ("'La dualidad del hombre griego", en Meditación de Europa [1949).

Tomo 10, pp.: 23 (Las dos alemanias [1908]), 52 y 54 (Sobre la pequeña filosofia [1908]), 70 (Disciplina, jefe, energia [1908]).

Tomo 12, p.: 237 (La razón histórica, V [1940]).

* Referencias a Schopenhauer en Epilogo. Notas de trabajo de José Ortega y Gasset -ed. Alianza Editorial, Madrid, 1994-:

Notas $n^{\circ} 136,262,304,333,487$.

13 . Ortega y Gasset, J., O.C.T.8, p.39.

14 "un hombre que debió de nacer viejo, todo arrugado ya, con su cara malhumorada de higo seco que filosofa." Ortega y Gasset, J.: Notas de trabajo, nota n $^{\circ} 304$.

15 Cf. Orringer, N.R., Ortega y sus fuentes germánicas, Madrd, 1979, ed. Gredos; y más concretamente para este punto Nuevas fuentes germánicas de "¿Qué es filosofía?" de Ortega, Madrid, 1984, C.S.I.C. También es de interés el libro de Morón Arroyo, C., El sistema de Ortega y Gasset, Madrid, 1968, ed. Alcalá. 
Tal vez lo más sorprendente de esta referencia a Schopenhauer sea que se produce en el contexto de la crítica de Ortega al idealismo - por más que aquel se reclame discípulo de Kant y su auténtico epígono-, escuela en la que le inserta de lleno $^{16}$ en tanto que postulante de un a priori intelectivo sobre la captación del mundo, que se convierte de esta manera en mera representación ideativa del sujeto cognoscente. El mundo desaparece en su realidad material, para ser una parte de la realidad representada en el sujeto, una representación de la conciencia.

Más adelante, en la lección IX de su curso, Ortega desmonta la pretensión idealista - iy, por tanto, schopenhaueriana! - de que del mundo solamente queda la "idea" del mundo. "El mundo no es mi representación [...]. Yo me represento el mundo. Lo mío aquí es el acto de representar y éste es un sentido claro de la palabra representación. Pero el mundo que me represento no es mi representarlo, sino lo representado. Lo mío es el representar, no lo representado. Schopenhauer confunde elementalmente en la sola palabra "representación" los dos términos cuya relación se trata precisamente de discutir, el pensar y lo pensado. ${ }^{17}$ "Sintéticamente, Ortega opone un rotundo "Sin objetos no hay sujeto" ${ }^{18}$, señalando la interdependencia radical "yo-circunstancia", una de las ideas a las que hace referencia su antigua metáfora de los Dei consentes de la mitología romana.

No se niega Ortega a acompañar durante un trecho al filósofo alemán en su idealismo. De hecho, las palabras de Schopenhauer parecen decir lo mismo que Ortega defiende: "[...] el mundo como representación, cualquiera que sea el aspecto bajo el cual le consideramos aquí, tiene dos mitades necesarias, esenciales e inseparables. La una es el objeto [...] la otra, el sujeto [... $]^{19}$ ". Lo que no admite es su reducción al subjetivismo. Para el filósofo alemán, sujeto y objeto se unifican en la representación. La mediación psicosensorial de la que se sirve la "intuición" intelectiva reduce el objeto a su capacidad de causación. No podemos alcanzar el conocimiento de los objetos, pues a lo más que puede llegar nuestra mente es a trabajar con las sensaciones aportadas por los sentidos.

Frente a esta idea de un mundo "representado" en el conocimiento a priori del sujeto ${ }^{20}$, Ortega sostiene que el mundo es la circunstancia del yo que lo conoce, y en la que conoce. Sin él es impensable la actividad cognoscitiva del sujeto, en la medida en que la "vida", en toda su concreción existencial, "nuestra vida", es, para

16 Ortega y Gasset, J., ¿Qué es filosofía?, O.C.T.7, p.377.

17 Ortega y Gasset, J., Op.cit. p.401.

18 Ortega y Gasset, J., Op.cit, p.402.

19 Schopenhauer, A., El mundo como voluntad y representación, p.20 (cito por la edición de Porrúa, México, 1992).

20 "[...] en términos generales, el objeto no existe más que para el sujeto, como su representación [...]". "[...] toda causalidad, o lo que es lo mismo, toda materia y, por consiguiente, toda realidad, no existe más que para el entendimiento, y por él y en él", Schopenhauer, Op.cit., p.25. 
Ortega, la "realidad radical". Por lo tanto, el hombre no adquiere su seguridad como existente, su autoconciencia, en tanto se descubre "pensando" — según la propuesta cartesiana-, sino en tanto que se encuentra "viviendo".

Por otra parte, el sujeto del conocimiento orteguiano realiza su función desde una "perspectiva" determinada, lo cual le proporciona una visión de la realidad siempre parcial, de luces y sombras, que dejan a la verdad siempre incompleta, en un continuo "haciéndose" en la serie de las perspectivas, logradas y por lograr, de todos los hombres a lo largo de todas las épocas. En el reconocimiento de las limitaciones que impone la exigencia de un conocimiento racional del mundo, Ortega critica a Schopenhauer su orientación irracionalista ${ }^{21}$, la cual sitúa en la estética ${ }^{22}$ musical la posibilidad — por otra parte, única— de acceder al "en sî" del mundo, por ser la música la expresión directa de la "voluntad"23.

\section{La metafísica de la "Voluntad", y la "Razón vital"}

A pesar de todo lo expuesto, tal vez el aspecto en el que Ortega se muestre más de acuerdo con Schopenhauer sea en su crítica global al idealismo alemán. En este punto son posibles algunas alianzas entre ambos filósofos. Libran la misma batalla, aunque indudablemente la guerra de uno y otro es muy diferente. En efecto. Si la caracterización exclusivamente representacional del mundo ya impide a Ortega acordar con Schopenhauer, la decantación del filósofo alemán hacia una consideración monopolar "vitalista" del ser del hombre, le hace merecedor de una nueva crítica.

Si Ortega había luchado también ferozmente contra el "idealismo", no era para después ensalzar y colocar en su lugar al "vitalismo". Para él, Schopenhauer representa una de las tres acepciones de lo que se entiende por "vitalismo": "Una filosofía cuyos últimos principios no son tomados de ningún conocimiento teorético sino de la impresión vital primaria, anterior y ajena a la intervención de la inteligencia ${ }^{24} "$. Esta unilateral radicalidad de lo vital es directamente contraria a la concepción dialéctica de la "Razón" y de la "Vida" que sostiene Ortega en El tema de nuestro tiempo (1921-22). El título de un breve escrito suyo posterior - $\mathrm{Ni}$ vitalismo ni racionalismo ${ }^{25}$ (1924)— es bastante elocuente de por sí. Allí, sin citar

21 "Schopenhauer había descubierto en la musicalidad un intérprete supremo de los arcanos cósmicos y hecho de ella una "metafísica sin conceptos". " Ortega y Gasset, J., O.C.T.2, p.337.

22 Para la convergencia de las ideas estéticas de Ortega con Schopenhauer remito al lector al artículo de Donald Santiago citado. También el artículo de Manuel Maceiras "Aproximaciones orteguianas al tema del Arte", en Aporia, n²1-24, 1983-1984, pp.83-105.

23 Schopenhauer, A., Op.cit., p.207.

24 Ortega y Gasset. J., Epilogo. Notas de Trabajo de José Ortega y Gasset, nota n487.

2s Ortega y Gasset, J., O.C.T.3, p.270. 
más que el nombre de Bergson, resume la tesis de la acepción anteriormente mencionada del vitalismo filosófico - "Se hace, pues, de la vida un método de conocimiento frente al método racional"-, a la que opone el vitalismo tal como él lo defiende: "La filosofía que no acepta más método de conocimiento teorético que el racional, pero cree forzoso situar en el centro del sistema idcológico el problema de la vida, que es el problema mismo del sujeto pensador de ese sistema." ${ }^{26}$ La vida como problema para el sujeto es, pues, el tema filosófico y cultural que Ortega situaba como el que su tiempo debía afrontar y dar respuesta.

Nuevamente nos encontramos con la metáfora de los Dei consentes. Sin "razón" no hay vida humana - no hay Bios, sino Zoos. Pero la razón encuentra su soporte existencial y su génesis en la urgencia de los requerimientos que, por su indeterminación vital, el ser humano encuentra a cada momento en la brega con su circunstancia. La crítica de Ortega se centra en la subversión que ha operado el racionalismo, al invertir la jerarquía que articula ambos componentes. El imperio de la "Idea" había terminado por satanizar todo aquello que fuera exaltación de las fuerzas vitales que operan en el mundo. El racionalismo, que arrancó en la Grecia socrática, había ido cavando un abismo entre el ser y el mundo. Su culminación hegeliana había colocado a la razón y la vida como pares antitéticos irreconciliables. Ortega asignaba a su generación la tarea de una profunda renovación filosófica y cultural consistente en volver a situar la "vida" en el centro de la razón de ser del hombre. No vivimos para pensar, sino que pensamos para poder vivir.

Pero el "vitalismo" orteguiano no es un mero vivir. Él no participa de esa "apología del activismo" ${ }^{27}$ que dice haber sido el punto de encuentro de los pensadores y artistas que realizaron la transición del siglo XIX al XX. Aquí también es breve el trayecto que ambos filósofos recorren juntos. Sería la energía ciega de la "voluntad" que postula Schopenhauer, si no fuera porque el hombre incorpora la razón como elemento rector de su existencia, razón que, a pesar de ser "breve isla rodeada de irracionalidad por todas partes", orienta al hombre en su tarea de existir. En último extremo, Ortega, como otros pensadores de su tiempo, lo que trataba a través de la reivindicación de la inmediatez de la vida era, paradójicamente, una revalorización de la razón, demasiado tiempo doblegada a los intereses transcendentes de determinada idea de lo que es la "Cultura". Se trataba, en definitiva, de "revitalizar la razón", no de "irracionalizar la vida".

Otra paradoja, aunque de signo bien distinto, del vitalismo postulado por Schopenhauer es su desembocamiento en la muerte. La vida, como parte de la voluntad que se manifiesta en energía ${ }^{28}$, en ciega actividad, no puede causar más

26. Ortega y Gasset, J., Op.cit. T.3.pp.272-273.

27 Ortega y Gasset, J., O.C.T.2, p.91.

28 No olvidemos la importante formación científica que tuvo Schopenhauer, y que queda patente en la cantidad de citas de este carácter que pueblan sus textos. 
que dolor en el hombre al someterse la condición unitaria y universal de aquella, al estado de concrección y multiplicación fenoménica de los seres. De aquí el conflicto, la lucha en que se resuelve el vivir, la existencia toda de cada quien con los demás, ya que cada ser es impulsado hacia la restitución de ese absoluto del que es participación. El dolor es, pues, irremediable. Ante él sólo queda la resignación, que abre la única ética ${ }^{29}$ posible para el hombre: avanzar por la vía de un ascetismo extremo que, al negar la voluntad, termina por anular al sujeto mismo. Después, la nada ${ }^{3()}$.

Indudablemente no podía dejar de repugnar a Ortega una filosofía que huye de la dialéctica para realizar toda su apuesta del lado de una metafísica monista. La "voluntad" domina, desborda a la razón sin considerarla. El hombre queda a merced de un Otro absoluto. El existir se desprende del viviente, dejándole como espectador doliente del capricho cósmico que en él se individualiza. El esfuerzo sintetizador de la dialéctica entre "razón" y "vida" que Ortega se afana en construir, no por criticar el racionalismo admite un vitalismo Amo del ser. Para Ortega, el existir también es lucha sí, continua e incansable. Pero el "dolor" no agota el registro de una existencia que se construye en cada momento de la vida. El dolor, la angustia es motor y acicate para que el sujeto se ponga en claro consigo mismo y en relación a su proyecto. Porque, precisamente, la existencia es construcción que realiza el sujeto con los actos de su existir. Su responsabilidad, pues, en el resultado de su existencia es plena e inalienable, sea en el logro de la realización de su "vocación", sea en el extravío de la "inautenticidad" en la que se hace ciego al requerimiento ético de aquella, y renuncia a sostener su individual e irrepetible perspectiva.

Frente al quietismo catatonizante de la propuesta schopenhaueriana, Ortega aboga por un uso "deportivo" del excedente energético en la vida humana, ya que no se agota en la faena continua del existir. Esta orientación de la vida es "vida ascendente" 31 , vida que aplica su vitalidad en la construcción, junto con los otros, del mundo en el que se realiza. Frente a la "nada" como solución a una existencia humana regida por una fuerza irracional e inmotivada, Ortega opone una vida que se afirma a sí misma en la producción de más vida. Es aquí donde la razón encuentra su lugar, dirigiendo esa vitalidad, y orientando su empleo en el logro de la realización de aquel programa de vida particular, concreto, individual, que cada ser humano ha de llevar a cabo si quiere dar toda su dimensión al hecho de vivir su vida.

20. Seguir esta ética supone, para Ortega, adscribirse a "la secta de los Asesinos del Viejo de la Montaña". Ortega y Gasset. J., Epilogo. Notas de Trabajo de José Ortega y Gasset, nota nº304.

31) Cf. Schopenhauer, A., Op.cit., p.315.

31 Cf. Ortega y Gasset, J., El Quijote en la escuela, O.C.T.2 


\section{OBRAS CITADAS}

GARAGORRI, Paulino. 1972. Unamuno y Ortega, Barcelona, Salvat / Madrid, Alianza, 1972.

GRAY, Rockwell. 1994. José Ortega y Gasset. El imperativo de la modernidad, Espasa Calpe, Madrid.

MACEIRAS FAFIAN, Manuel. 1985. Schopenhauer y Kierkegaard: sentimiento y pasión, Cincel, Madrid.

- 1983-1984. "Aproximaciones orteguianas al tema del Arte", en Aporía, $\mathrm{n}^{\circ}$ 21-24, pp. 83-105.

MORÓN ARROYO, C.. 1968. El sistema de Ortega y Gasset, Alcalá, Madrid.

ORRINGER, Nelson.R. 1979. Ortega y sus fuentes germánicas, Gredos, Madrid.

- 1984. Nuevas fuentes germánicas de "¿Qué es filosofía?" de Ortega, C.S.I.C., Madrid.

ORTEGA Y GASSET, José. 1987. Obras Completas, Alianza Editorial, Madrid.

- 1994. Epílogo. Notas de trabajo de José Ortega y Gasset, Alianza Editorial, Madrid.

SANTIAGO, Donald. 1993. "La rccepción de Schopenhauer en España", en Anthropos, col. Documentos n6, octubre, pp. 146-155.

SCHOPENHAUER, Arthur. 1992. El mundo como voluntad y representación, Porrúa, México. 